\title{
Energy conservation at school and home
}

\author{
Cameron Lago and Mike Pham
}

\section{Abstract}

We do not always think of the impact we are making on the climate every time we turn on a light, use a computer or watch T.V. For this research-informed action research project we studied how electricity usage can impact the climate. We conducted a mini correlational study at Erindale Secondary School to learn more about our peers' electricity consumption. We asked our peers how many fluorescent light bulbs they use in their homes, and how often they turn off their lights when they leave the room. Our mini study reveals that the majority of boys and girls do not know how many light bulbs in their homes are energy efficient. In addition, equal proportion of girls and boys always or sometimes turn off the lights when they are not in use. For the action portion of our project, we organized the Earth Hour at our school to lower the energy consumption and to raise awareness about the importance of energy conservation. The Principal of our school also agreed to turn off the lights in the cafeteria every night to save more energy. We also challenged David Suzuki Secondary School in Mississauga to a friendly competition to see which school will save more energy. We still await the electricity usage data from the board to see who won the challenge. 


\section{Introduction}

Much of our developed world has become an increasingly consumerbased society. Consumers want more and more electronic devices to keep up to the modern times. Between the year 2008 and 2030, it is estimated that the world's energy consumption will increase by $55 \%$. (" 55 Interesting Facts,” 2012) Citizens, corporations, and governments all have a responsibility to ensure that our planet is not harmed by the greenhouse gases emitted as a result of increased energy demand.

Currently, there are various methods by which energy can be generated. For example: hydroelectricity, solar, wind, nuclear, geothermal, petroleum, coal, and biofuels are the most common renewable and non-renewable methods. Each method has its own advantages and disadvantages for the wellbeing of individuals, societies and environments. The emission of greenhouse gases by combustion of non-renewable fossil fuel is a major concern for the environment as addition carbon dioxide may cause increased average global temperatures. The effects of climate change are well known. For example, droughts are becoming more common in the world as a result of sever heat waves in places like Kenya, Ethiopia and Somalia. As a result of droughts, crops will not yield properly due to lack of water. Some families depend on agriculture to survive. Therefore, droughts cause food shortages and loss of income for many families dependent on agriculture. Entire communities can be affected, and in many cases, children, who are the most vulnerable, die of hunger.

Much of our energy in Ontario comes from nuclear power. Although nuclear energy is efficient, it has some negative effects, too. The nuclear waste is put into storage tanks for long periods of time to ensure no humans or other living things come in contact. Some quantities of radioactive and other types of nuclear waste take between 200-500 thousand years to decompose (Shedroff, 2003). The possibility of nuclear waste leaking into our ground and contaminating our water is a concern.

Alternative methods to electricity generation, such as solar and wind power, may be cleaner and safer. The problem of efficiency and environmental concerns (especially over wind power) need to be addressed. Presently, our society and our environment can benefit greatly if we all become more conscious of how much electricity we use. By simply cutting down on our energy consumption we can limit the amount of GHGs emitted and slow down the effects of climate change.

\section{Focus Of Our Study}

We conducted a mini study involving 50 girls and 50 boys at Erindale Secondary School to learn more about their energy consumption habits. We designed a simple survey consisting of two questions. First, we asked the participants to identify their gender. Then we asked them to answer two questions: i) how many compact fluorescent bulbs to they have at home, and ii) how often do they turn off lights after they are not in use. We collected the data over lunch periods and tallied it after to produce bar graphs. 

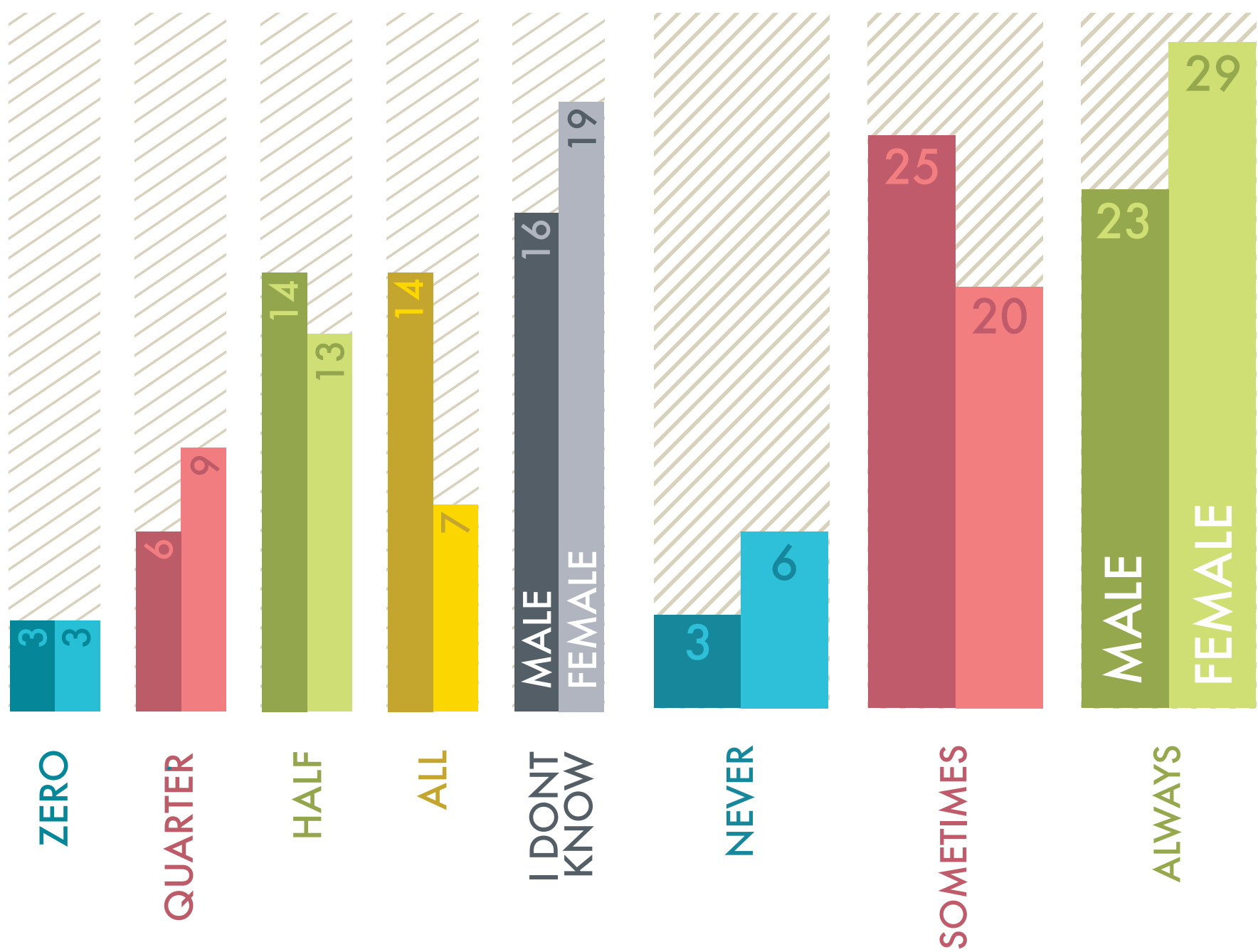

Figure 1: Results obtained for the questions: "How many fluorescent light bulbs do you use in your home."

Figure 2: Do You Turn Off The Lights When You Leave The Room?

\section{Results Of The Study}

Figure 1 shows the results from the first question that we asked. The data shows that 16 males and 19 females do not know if their home is supplied with compact fluorescent light bulbs. In addition, 15 males and 7 females knew that they had all fluorescent light bulbs; 14 males and 13 females reported that half of their light bulbs were compact fluorescent; 6 males and 4 females had a quarter of their bulbs as compact fluorescent; and 6 students, 3 of each gender, did not have any compact fluorescent light bulbs in their home.

Figure 2 shows how often students turn off their lights when the lights are not in use. The majority of the students either sometimes or always turn off the lights when they leave a room. To be exact, 25 males and 20 females sometimes turn the lights off; and 23 males and 29 females are in the habit of always turning off the lights. However, 3 males and 6 females never turn off the lights when they leave a room. 


\section{Discussion}

There appears to be no correlation between gender and one's awareness of how many light bulbs are present in one's home. In fact, it appears that the majority of the students, males and females, are not aware of how many light bulbs in their home are energy efficient. Since teenagers do not generally buy light bulbs, it makes sense that they would not have too much awareness. We argue that teenagers should be more proactive. They should become more aware of how energy efficient their homes are. They should discuss this with their parents/guardians and make their homes (and schools) more energy efficient.

Furthermore, there is no correlation between gender and how often one turns off lights when lights are not in

\section{Taking Action}

We took several actions to address the issue of energy consumption, primary at school. We hope that the actions we take will have an effect on one's energy consumption at home as well.

First, we lobbied our school Principal to turn off the lights in the school cafeteria when cafeteria was not in use. Given that our school is an eco-friendly school, our Principal supported our initiative in hope of conserving energy.

Second, with the help of our teacher and our Principal, we obtained electricity usage data for our school for the last five years. Our Principal phoned another principal at David Suzuki Secondary School and challenged the school to a friendly competition to see which school could save more energy by the end of the 2013 school year. We still need to obtain the most current data from the board to see who won the challenge. use. Most girls and boys reported that they turn off lights sometimes or always. A slightly greater number of girls turn off lights more often than boys. This could possibly be the Furthermore, there is no correlation between gender and how often one turns off lights when lights are not in use. Most girls and boys reported that they turn off lights sometimes or always. A slightly greater number of girls turn off lights more often than boys. This could possibly be the case because teenage girls are stereotypically more responsible than boys. We think that a greater portion of girls and boys should always be turning off their lights when they leave a room. This would conserve more energy and benefit the environment.
Third, we encouraged all teachers to participate in the Earth Hour. We made regular morning announcements prior to the Earth Hour date. Also, we created an information slip for all teachers outlining facts and conversation starters about electricity usage. Teachers would share this information with their students during the Earth Hour, if they wished.

In conclusion, we hope that we were able to inspire at least one person to begin their own journey for a more aware society when it comes to energy consumption. Even if we reached one person, we would feel as if we have completed our goal in the end. We wish that everyone will become aware of our deteriorating Earth and that everyone will take an action towards a more desirable Earth to live in.

Citizens, corporations, and governments can all say that change will take place; however, words can't change a problem, taking action can!

\section{References}

55 interesting facts about energy. (March 30, 2012). Retrieved from http://facts.randomhistory.com/energy-facts.html Shedroff, N. (February , 2009 23). Nuclear energy: Pros and cons . Retrieved from http://www.triplepundit.com/2009/02/nuclear-energy-pros-and-cons/ 